1 NOTICE: this is the author's version of a work that was accepted for publication in Chemical Geology.

2 Changes resulting from the publishing process, such as peer review, editing, corrections, structural

3 formatting, and other quality control mechanisms may not be reflected in this document. Changes may

4 have been made to this work since it was submitted for publication. A definitive version was

5 subsequently published in Chemical Geology 200, 105-115. http://dx.doi.org/10.1016/s0009-

$6 \underline{2541(03) 00161-x}$

7

8

9 Modelling molybdate and tungstate adsorption

\title{
to ferrihydrite
}




\section{Abstract}

2

3 The environmental geochemistry of molybdenum and tungsten is not well known.

4 To enable predictions of Mo and W concentrations in the presence of ferrihydrite

5 ("hydrous ferric oxide"), batch equilibrations were made with $\mathrm{MoO}_{4}{ }^{2-}, \mathrm{WO}_{4}{ }^{2-}, \mathrm{PO}_{4}{ }^{3-}$

6 and freshly prepared ferrihydrite suspensions in $0.01 \mathrm{M} \mathrm{NaNO}_{3}$ in the $\mathrm{pH}$ range from

73 to 10 at $25^{\circ} \mathrm{C}$. The results showed that $\mathrm{WO}_{4}{ }^{2-}$ is adsorbed more strongly than $\mathrm{MoO}_{4}{ }^{2-}$

8 , and that both ions are able to displace $\mathrm{PO}_{4}{ }^{3-}$ from adsorption sites at low $\mathrm{pH}$. Two

9 models, the diffuse layer model (DLM) and the CD-MUSIC model (CDM) were

10 tested in an effort to describe the data. In both models, the adsorption of $\mathrm{MoO}_{4}{ }^{2-}$ and

$11 \mathrm{WO}_{4}{ }^{2-}$ could be described with the use of two monodentate complexes. One of these

12 was a fully protonated complex, equivalent to adsorbed molybdic or tungstic acid,

13 which was required to fit the data at low $\mathrm{pH}$. This was found to be the case also for a

14 data set with goethite. In competitive systems with $\mathrm{PO}_{4}{ }^{3-}$, the models did not always

15 provide satisfactory predictions. It was suggested that this may be partly due to the

16 uncertainty in the $\mathrm{PO}_{4}{ }^{3-}$ complexation constants.

17

18 Keywords: Molybdenum; Tungsten; Hydrous Ferric Oxide; Surface Complexation;

19 Modelling

\section{1. Introduction}

24 Molybdenum is an essential trace element for both plants and animals.

25 Molybdenum deficiency has often been reported, but at large concentrations Mo may 
1 be toxic as it leads to secondary Cu deficiency (e.g. Murphy and Walsh, 1972;

2 Vunkova-Radeva et al., 1988). Of particular concern is the release of Mo from

3 alkaline ashes when used as secondary materials (Jacks, 1983; Meima et al., 2002).

4 Tungsten is an important strategic metal that is used in a variety of industrial

5 applications. It is usually mined from deposits of scheelite $\left(\mathrm{CaWO}_{4}\right)$, and wolframite

$6 \quad(\mathrm{Fe}, \mathrm{Mn}) \mathrm{WO}_{4}$. Tungsten is released to the environment, e.g. through its use in winter

7 tires. The biogeochemical behaviour of $\mathrm{W}$ is poorly known. However, it is known that

8 the $\mathrm{WO}_{4}{ }^{2-}$ ion has an antagonistic effect on the metabolism of $\mathrm{MoO}_{4}{ }^{2-}$ (Mikkonen and

9 Tummavuori, 1993).

11 At relatively high $\mathrm{Eh}, \mathrm{Mo}$ and $\mathrm{W}$ are present in their hexavalent state, i.e. as $\mathrm{MoO}_{4}{ }^{2-}$ 12 and $\mathrm{WO}_{4}{ }^{2-}$, and their derivatives. From equilibrium modelling it can be predicted that 13 the fully dissociated $\mathrm{MoO}_{4}{ }^{2-}$ and $\mathrm{WO}_{4}{ }^{2-}$ ions predominate over the non-dissociated 14 forms at $\mathrm{pH}>4.4$ in dilute waters (Cruywagen, 2000, Smith et al., 2001). At $\mathrm{pH}<$ 15 4.4, the ions will protonate to form the acids $\mathrm{MoO}_{3}\left(\mathrm{H}_{2} \mathrm{O}\right)_{3}$ and $\mathrm{WO}_{3}\left(\mathrm{H}_{2} \mathrm{O}\right)_{3}$, in which 16 Mo and W coordinate six oxygens instead of four. At large concentrations ( $>1-10$ $17 \mu \mathrm{M})$, Mo and $\mathrm{W}$ polymerise to a variety of different polymolybdate / tungstate forms, 18 particularly at low $\mathrm{pH}$ (Cruywagen, 2000). In solution, a wide range of complexes 19 with organic acids has been reported (e.g. Cruywagen et al., 1995).

21 The geochemical behaviour of $\mathrm{MoO}_{4}{ }^{2-}$ and $\mathrm{WO}_{4}{ }^{2-}$ in the environment is probably 22 dependent to a large extent on adsorption reactions to particle surfaces. In soils, it is 23 found that these ions were bound most strongly at low $\mathrm{pH}$ (Mikkonen and 24 Tummavuori, 1993; 1994; Bibak and Borggaard, 1994). 
1 Iron, aluminium and to some extent titanium oxides may be important sorbent

2 minerals for $\mathrm{MoO}_{4}{ }^{2-}$ and $\mathrm{WO}_{4}{ }^{2-}$, as they may acquire positive charge at low $\mathrm{pH}$ (Bibak

3 and Borggaard, 1994; Rietra et al., 1999; Bourikas et al., 2000). The binding

4 mechanism to these oxides is thought to be surface complexation, either as mono- or

5 bidentate complexes (e.g. Manning and Goldberg, 1996; Bourikas et al., 2000).

6 Goldberg and colleagues studied the adsorption of molybdate onto goethite, gibbsite

7 and clay minerals (e.g. Goldberg et al. 1996; Manning and Goldberg, 1996; Goldberg

8 and Forster, 1998). They found that adsorption is very strong at low $\mathrm{pH}$; in this $\mathrm{pH}$

9 region molybdate is able to compete well even with the very strongly sorbing $o$ -

10 phosphate $\left(\mathrm{PO}_{4}{ }^{3-}\right)$ ion. However, molybdate adsorption exhibited a very strong $\mathrm{pH}$

11 dependence, and at $\mathrm{pH}>8-9$ little Mo was adsorbed. These authors used a surface

12 complexation model, the Constant Capacitance Model (CCM), to describe the data

13 obtained with the use of two Mo surface complexes.

15 For the adsorption of $\mathrm{MoO}_{4}{ }^{2-}$ to 2-line ferrihydrite ("hydrous ferric oxide"), data 16 sets are rather sparse. Two exceptions are small data sets published by Balistrieri and 17 Chao (1990) and Bibak and Borggaard (1994), which follow the general trend 18 described above for goethite. No data set has been found that treats the adsorption of $19 \mathrm{WO}_{4}{ }^{2-}$ to ferrihydrite. In their compilation of constants for the Diffuse Layer Model 20 (DLM), Dzombak and Morel (1990) did not fit any data sets for $\mathrm{MoO}_{4}{ }^{2-}$ and $\mathrm{WO}_{4}{ }^{2-}$; 21 instead they estimated constants using linear-free energy relationships (LFER).

23 A third surface complexation model is CD-MUSIC (Hiemstra and Van Riemsdijk, 24 1996), which was used to describe $\mathrm{MoO}_{4}{ }^{2-}$ adsorption to titania (Bourikas et al., 25 2001). Their model suggested $\mathrm{MoO}_{4}{ }^{2-}$ adsorption to be dominated by a bidentate 
1 complex at low $\mathrm{pH}\left(\mathrm{Ti}_{2} \mathrm{O}_{2} \mathrm{MoO}_{2}\right)$ and by a monodentate complex $\left(\mathrm{TiMoO}_{3}\right)$ at high

$2 \mathrm{pH}$. In line with this, Rietra et al. (1999) suggested a bidentate complex $\left(\mathrm{Fe}_{2} \mathrm{O}_{2} \mathrm{MoO}_{2}\right)$

3 to dominate the speciation of adsorbed Mo to goethite, as judged from measurements

4 of the proton coadsorption stoichiometry at $\mathrm{pH} 4.2$ and $\mathrm{pH} 6.1$.

5

6 The objectives of this study were to supply data on the adsorption of $\mathrm{MoO}_{4}{ }^{2-}$ and

$7 \mathrm{WO}_{4}{ }^{2-}$ to 2 -line ferrihydrite at different $\mathrm{pHs}$ and surface coverages, to discuss the

8 effect of competing $\mathrm{PO}_{4}{ }^{3-}$ ions, and to apply two surface complexation models (DLM

9 and CD-MUSIC) in an effort to describe the data obtained. To my knowledge, this is

10 the first time the adsorption of $\mathrm{WO}_{4}{ }^{2-}$ to ferrihydrite has been studied in this manner.

11 For the DLM, it was hypothesized that the constants previously estimated from LFER 12 could describe the data accurately.

\section{Methods}

\subsection{Laboratory procedures}

Ferrihydrite was synthesized using a method adapted from Swedlund and Webster (1999) and Schwertmann and Cornell (2000). Briefly, a solution containing $36 \mathrm{mM}$ $\mathrm{Fe}\left(\mathrm{NO}_{3}\right)_{3}$ and $12 \mathrm{mM} \mathrm{NaNO}_{3}$ was brought to $\mathrm{pH} 8.0$ through dropwise addition of 4 $\mathrm{M} \mathrm{NaOH}$. The resulting suspension was aged for $18-22 \mathrm{~h}$ at $20^{\circ} \mathrm{C}$. This procedure has been shown to produce 2-line ferrihydrite with a BET $\left(\mathrm{N}_{2}\right)$ surface area in the range of 200-320 $\mathrm{m}^{2} \mathrm{~g}^{-1}$ (Swedlund and Webster, 1999; Schwertmann and Cornell, 2000). However, the exact value is strongly dependent on the outgassing conditions, which are seldom reported (Clausen and Fabricius, 2000). Moreover it is believed that the $\operatorname{BET}\left(\mathrm{N}_{2}\right)$ method underestimates the real surface area of ferrihydrite considerably, 
1 probably because of aggregation of nanoparticles, which makes part if the surface

2 inaccessible to the $\mathrm{N}_{2}$ sorbate (Dzombak and Morel, 1990; Schwertmann and Cornell,

3 2000). For these reasons, BET surface areas are of limited interest for the

4 characterization of 2-line ferrihydrite and they can probably not be used for modelling

5 purposes. Hence they were not measured. Instead, surface areas of 600 and $750 \mathrm{~m}^{2} \mathrm{~g}^{-1}$

6 was assumed for the 2-pK DLM (Dzombak and Morel, 1990; Swedlund and Webster,

7 1999) and for the 1-pK CDM (Gustafsson, 2001), respectively, see below. These areas

8 are in better agreement with the surface area inferred from theoretical grounds

9 (Dzombak and Morel, 1990; Schwertmann and Cornell, 2000).

11 Before the batch experiments, the ferrihydrite suspension was back-titrated to $\mathrm{pH}$

124.6 with $0.1 \mathrm{M} \mathrm{HNO}_{3}$ and vigorously shaken for $15 \mathrm{~min}$. Batch experiment

13 suspensions was prepared by mixing an amount of ferrihydrite suspension with stock

14 solutions of $\mathrm{NaNO}_{3}$ and the appropriate anion salt (as $\mathrm{Na}_{2} \mathrm{MoO}_{4}, \mathrm{Na}_{2} \mathrm{WO}_{4}$ or

$\left.15 \mathrm{NaH}_{2} \mathrm{PO}_{4}\right)$, to obtain suspensions with an ionic strength of $0.01 \mathrm{M}\left(\right.$ as $\left.\mathrm{NaNO}_{3}\right)$.

16 Various amounts of acid (as $\mathrm{HNO}_{3}$ ) or base (as $\left.\mathrm{NaOH}\right)$ was added to produce a range

17 of pHs. In the single-sorbate systems, only one anion (except $\mathrm{NO}_{3}{ }^{-}$) was added at

18 concentrations of $50 \mu \mathrm{M} \mathrm{MoO}_{4}{ }^{2-}, 50 \mu \mathrm{M} \mathrm{WO}_{4}{ }^{2-}$ or $200 \mu \mathrm{M} \mathrm{PO}_{4}{ }^{3-}$; in these systems,

19 anion sorption was studied at three different concentrations of ferrihydrite, which

20 contained $0.3,1$ and $3 \mathrm{mM}$ total $\mathrm{Fe}$ (however, there was no $\mathrm{PO}_{4}{ }^{3-}$ system with $0.3 \mathrm{mM}$

$21 \mathrm{Fe}$ ). In the binary (competitive) systems, the ferrihydrite concentration was $1 \mathrm{mM}$ as

22 total $\mathrm{Fe}$, whereas the anion concentrations were either $50 \mu \mathrm{M} \mathrm{MoO}_{4}{ }^{2-}+200 \mu \mathrm{M} \mathrm{PO}_{4}{ }^{3-}$

23 or $50 \mu \mathrm{M} \mathrm{WO}_{4}{ }^{2-}+200 \mu \mathrm{M} \mathrm{PO}_{4}{ }^{3-}$. The samples were equilibrated in $40 \mathrm{ml}$

24 polypropylene centrifuge tubes. 
After $24 \mathrm{~h}$ equilibration in a shaking water bath at $25^{\circ} \mathrm{C}$, the samples were centrifuged for $30 \mathrm{~min}$ at about $5000 \mathrm{~g}$, and filtered using $0.2-\mu \mathrm{m}$ single-use filters (Acrodisc PF). The $\mathrm{pH}$ was measured on the unfiltered sample, using a Radiometer combination electrode. The filtered suspension was acidified $\left(0.5 \% \mathrm{HNO}_{3}\right)$ and analysed for $\mathrm{W}$, Mo and $\mathrm{P}$ with plasma emission spectroscopy using a Jobin-Yvon JY24 ICP instrument. Preliminary experiments with $\mathrm{WO}_{4}{ }^{2-}$ spikes in acidified solutions in polypropylene containers showed that the $\mathrm{WO}_{4}{ }^{2-}$ concentration started to decrease after a few days, probably because of the formation of an insoluble surface phase on the container walls. To avoid this, analysis was carried out within $24 \mathrm{~h}$ of filtration, to avoid the risk for $\mathrm{WO}_{4}{ }^{2-}$ loss from solution due to its slow adsorption to the container walls.

\subsection{Modelling}

The surface complexation models used were the 2-pK DLM (according to Dzombak and Morel, 1990), and the 1-pK CDM with the Three-Plane interface model (Hiemstra and Van Riemsdijk, 1996; 1999). I used the same DLM parameters as Dzombak and Morel (1990): a specific surface area of $600 \mathrm{~m}^{2} \mathrm{~g}^{-1}$ was assumed, the site density was fixed at $0.205 \mathrm{~mol} \mathrm{~mol}^{-1} \mathrm{Fe}$, and the $\log K: \mathrm{s}$ of the surface complexation reactions defining the formation of the protonated $\mathrm{FeOH}_{2}{ }^{+}$species and the deprotonated $\mathrm{FeO}^{-}$ species were set at 7.29 and -8.93 , respectively. Table 1 shows the surface complexation reactions involving $\mathrm{Mo}, \mathrm{W}$ and $\mathrm{P}$.

For the CDM, I used the surface charging parameters as was suggested in an earlier study (Gustafsson, 2001): a specific surface area of $750 \mathrm{~m}^{2} \mathrm{~g}^{-1}$, a site density of 0.443 mol mol ${ }^{-1} \mathrm{Fe}$ of singly coordinated $\mathrm{FeOH}$ groups, a $\log K$ for the formation of 
$1 \mathrm{FeOH}_{2}{ }^{1 / 2+}$ of $8.1, \log K$ :s for the ion-pair complexes $\mathrm{FeOHNa}^{1 / 2+}$ and $\mathrm{FeOH}_{2} \mathrm{NO}_{3}{ }^{1 / 2-}$ of -

20.4 and 7.2, respectively, an inner capacitance of $1.3 \mathrm{~F} \mathrm{~m}^{-2}$, and an outer capacitance

3 of $5 \mathrm{~F} \mathrm{~m}^{-2}$. Table 2 lists the other surface complexation reactions considered.

5 In the modelling, I considered the protonation reactions of the $\mathrm{MoO}_{4}{ }^{2-}$ and $\mathrm{WO}_{4}{ }^{2-}$ 6 ions:

7

$$
\begin{aligned}
& \mathrm{H}^{+}+\mathrm{XO}_{4}{ }^{2-} \leftrightarrow \mathrm{HXO}_{4}^{-}, K_{1} \\
& 2 \mathrm{H}^{+}+\mathrm{XO}_{4}{ }^{2-}+2 \mathrm{H}_{2} \mathrm{O} \leftrightarrow \mathrm{XO}_{3}\left(\mathrm{H}_{2} \mathrm{O}\right)_{3}, K_{2}
\end{aligned}
$$

9 Here $\mathrm{X}$ is Mo or W, whereas $K_{1}$ and $K_{2}$ are equilibrium constants. For Mo, $\log K_{1}$ 10 and $\log K_{2}$ were set to 4.24 and 8.24 , respectively, using the most recent NIST

11 reference database values (Smith et al., 2001). For W, I used $\log K_{1}=3.62$

12 (Wesolowski et al., 1984) whereas $\log K_{2}=8.7$ was estimated from extrapolation of 13 data obtained by Wood and Samson (2001) to room temperature. The model fits was 14 not sensitive to the exact value of these constants, as most data were collected at $\mathrm{pH}>$ 15 5. Polymeric Mo and W species were considered using the $1 \mathrm{M}$ constants compiled by 16 Cruywagen (2000), which had been extrapolated to $0 \mathrm{M}$ ionic strength using the 17 Davies equation. However, the polymeric species were found to be insignificant in 18 this study. The chemical equilibrium program Visual MINTEQ (Gustafsson,

21 http://www.lwr.kth.se/English/OurSoftware/vminteq/index.htm) was used to produce 22 model fits with previously determined surface complexation constants. To optimise 23 new surface complexation constants, FITEQL 4.0 was used (Herbelin and Westall, 
1 1999), which is a non-linear least-squares optimisation program. In the standard

2 version, FITEQL 4.0 contains the DLM, but not the CDM. Therefore, to deal with the

3 results from this study, FITEQL 4.0 was modified to include the Three-Plane interface

4 model and to permit the non-zero charge of the reference oxide component, as

5 required by the $1-\mathrm{p} K \mathrm{CDM}$. In addition, the constants of multidentate surface species

6 were redefined on a mole fraction basis (Hiemstra and Van Riemsdijk, 1996).

7 Obtained equilibrium constants were averaged using the weighting method of

8 Dzombak and Morel (1990), in which the weighting factor $w_{i}$ is defined as

9

$$
w_{i}=\frac{\left(1 / \sigma_{\log K}\right)_{i}}{\sum\left(1 / \sigma_{\log K}\right)_{i}}
$$

11 where $\left(\sigma_{\log K}\right)_{i}$ is the standard deviation of $\log K$ calculated by FITEQL for the $i^{\text {th }}$ 12 data set. The best estimate for $\log K$ is then calculated as:

$$
\overline{\log K}=\sum w_{i}(\log K)_{i}
$$

\section{Results}

\subsection{Single-sorbate systems}

21 A detailed account of the results obtained can be found in Table 3. Molybdate

22 adsorption was strongly pH-dependent (Fig. 1, Table 3), which is consistent with 
1 earlier studies. Even at the highest surface coverage $(0.3 \mathrm{mM} \mathrm{Fe})$, almost $100 \%$ was

2 adsorbed at low $\mathrm{pH}$, whereas little Mo adsorption occurred at $\mathrm{pH}>9$ at all surface

3 coverages. For $\mathrm{MoO}_{4}{ }^{2-}$, there was considerable scatter in the adsorption envelopes. It

4 is possible that errors in $\mathrm{pH}$ measurements may in part explain this, as most $\mathrm{pH}$ values

5 were in the circumneutral region ( $\mathrm{pH}$ 6-8), where the ferrihydrite suspensions were

6 extremely poorly buffered.

8 Tungstate adsorption was also strongly pH-dependent (Fig. 2, Table 3). At low

9 surface coverage, the adsorption envelopes were shifted almost $2 \mathrm{pH}$ units upwards

10 compared with molybdate, which shows that $\mathrm{WO}_{4}{ }^{2-}$ was adsorbed much more

11 strongly than $\mathrm{MoO}_{4}{ }^{2-}$ to ferrihydrite. The higher $\mathrm{pH}$ probably explains the smaller

12 degree of scatter in the $\mathrm{WO}_{4}{ }^{2-}$ adsorption envelopes.

14 When Dzombak and Morel's DLM constants for $\mathrm{MoO}_{4}{ }^{2-}$ (as estimated by LFER)

15 were used (Table 1), I found that the adsorption of $\mathrm{MoO}_{4}{ }^{2-}$ was underestimated 16 slightly at the two lower surface coverages (Fig. 1, dotted lines). At the highest

17 surface coverage, the constants were quite unable to describe the near $100 \%$

18 adsorption occurring at low $\mathrm{pH}$. To improve the DLM description of $\mathrm{MoO}_{4}{ }^{2-}$ binding,

19 a fully protonated species D1 had to be included in the model; this is referred to as

$20 \mathrm{FeOMo}(\mathrm{OH})_{5}$ in Table 1, and may be thought of as adsorbed molybdic acid. The

21 FITEQL optimisation led to reasonable results either with a combination of species

22 D1 and D3, or with a combination of species D1 and D2. Of these combinations, the

23 former was chosen because a slightly better fit was obtained. Table 4 shows the

24 optimisation results and the solid line of Fig. 1 the actual fit (solid line). 
1 For $\mathrm{WO}_{4}{ }^{2-}$, Dzombak and Morel's LFER constants severely underestimated the

2 adsorption at all surface coverages (Fig. 2). Again, I used a combination of two

3 surface species (D4 and D6) in the FITEQL optimisations, and was able to produce a

4 good fit to the results, with SOS/DF values of $<10$ for all three systems (Table 4). Of

5 course, the optimised constants were larger than those of $\mathrm{MoO}_{4}{ }^{2-}$, reflecting the

6 stronger affinity of $\mathrm{WO}_{4}{ }^{2-}$.

8 When I optimised constants for the CDM, I assumed that the CD value (i.e. the

9 fraction of the charge of the central atom in the complex that is distributed towards the

$10 o$-plane) for $\mathrm{XO}_{4}{ }^{2-}$ bidentate complex is 0.5 , whereas it is 0.25 for a monodentate

11 complex, in line with the optimal values discussed by Rietra et al. (1999). This results

12 in the stoichiometry of the electrostatic components $P_{o}$ and $P_{b}$ shown in Table 2. First,

13 it was examined whether the bidentate complexes $\mathrm{Fe}_{2} \mathrm{O}_{2} \mathrm{MoO}_{2}$ or $\mathrm{Fe}_{2} \mathrm{O}_{2} \mathrm{WO}_{2}$ could

14 provide satisfactory fits to the data, either alone or in combination with a monodentate

15 complex. However, very poor fits were obtained, particularly in the absence of the

16 fully protonated monodentate complexes $\mathrm{C} 1$ and $\mathrm{C} 3$ (Table 2), which were found to

17 be necessary to describe the low $\mathrm{pH}$ data. In fact, it was found that the best fits were

18 obtained when the bidentate complexes were left out completely from the

19 optimisation. Instead it was found that a combination of the monodentate $\mathrm{C} 1$ and $\mathrm{C} 2$

20 complexes provided reasonable fits to the $\mathrm{MoO}_{4}{ }^{2-}$ data (Table 5). For $\mathrm{WO}_{4}{ }^{2-}$, good fits

21 were obtained with the analogous combination (C3 and $\mathrm{C} 4)$.

23 For $\mathrm{PO}_{4}{ }^{3-}$, Dzombak and Morel's DLM constants provided a rather good fit to the

24 data, whereas my previously estimated CDM constants (Gustafsson, 2001) provided a

25 poor fit (Fig. 3). The only available data set amenable to the extraction of 
1 complexation constants by FITEQL was the one at $1 \mathrm{mM} \mathrm{Fe}$, as almost all data at 3

$2 \mathrm{mM}$ Fe showed $100 \%$ adsorption (Table 3). For the purpose of predicting $\mathrm{P}$

3 competition effects on the adsorption of Mo and W, new constants were optimised

4 (Tables 4 and 5), resulting in the fits shown in Fig. 3. Since I used an unrealistically

5 large $\mathrm{CD}$ value for the monodentate $\mathrm{C} 5$ complex in my previous work (Gustafsson,

6 2001), it was decreased to 0.3 in this study, which would be the case if the charge of

7 the surface oxygen in the complex is fully neutralized. In FITEQL, rather large

8 standard deviations were obtained for the optimised $\mathrm{PO}_{4}{ }^{3-}$ surface complexation

9 constants (Tables 4 and 5). This indicates that the complexation constants were not

10 fully constrained from this data set and therefore they should be regarded as crude

11 estimates.

\subsection{Competitive interactions}

14 In the presence of $200 \mu \mathrm{M}$ added $\mathrm{PO}_{4}{ }^{3-}$, the $\mathrm{MoO}_{4}{ }^{2-}$ adsorption envelope was

15 shifted almost $2 \mathrm{pH}$ units to the left on the $\mathrm{pH}$ scale (Fig. 4). However, despite the strong competition from $\mathrm{PO}_{4}{ }^{3-}, \mathrm{MoO}_{4}{ }^{2-}$ adsorption still approached $100 \%$ at $\mathrm{pH}<4$.

17 With DLM, the results were simulated well, except at $\mathrm{pH}<4.5$, where DLM

18 overestimated the dissolved $\mathrm{MoO}_{4}{ }^{2-}$ concentration. The CDM provided a less

19 satisfying fit, as the dissolved $\mathrm{MoO}_{4}{ }^{2-}$ concentration was underestimated considerably

20 below $\mathrm{pH}$ 6.5. For both models, it was found that the fully protonated surface species

21 (D1 and C1) dominated the Mo surface speciation completely, whereas the less

22 protonated species (D3 and C2) had almost disappeared because of $\mathrm{PO}_{4}{ }^{3-}$ competition.

24 The $\mathrm{WO}_{4}{ }^{2-}+\mathrm{PO}_{4}{ }^{3-}$ system displayed a similar behaviour although the $\mathrm{WO}_{4}{ }^{2-}$ ions 25 were displaced less easily than $\mathrm{MoO}_{4}{ }^{2-}$, in agreement with the stronger overall 
1 adsorption of $\mathrm{WO}_{4}{ }^{2-}$ (Fig. 5). At $\mathrm{pH}<5.5$, almost $100 \%$ was adsorbed. In this case,

2 the DLM could not predict the $\mathrm{WO}_{4}{ }^{2-}$ concentration satisfactorily, as adsorption was

3 underestimated, particularly at high $\mathrm{pH}$. For the $\mathrm{CDM}$, however, $\mathrm{WO}_{4}{ }^{2-}$ adsorption

4 was predicted rather well.

5

6 Because $\mathrm{MoO}_{4}{ }^{2-}$ and $\mathrm{WO}_{4}{ }^{2-}$ adsorbed strongly at low $\mathrm{pH}$ despite the competition

7 from $\mathrm{PO}_{4}{ }^{3-}$, it was not surprising that the adsorption of $\mathrm{PO}_{4}{ }^{3-}$ was affected. As Fig. 6

8 implies, the presence of $\mathrm{MoO}_{4}{ }^{2-}$ or $\mathrm{WO}_{4}{ }^{2-}$ caused a strong effect on the dissolved

$9 \mathrm{PO}_{4}{ }^{3-}$ concentration. Tungstate was found to affect $\mathrm{PO}_{4}{ }^{3-}$ adsorption the most, in

10 agreement with the finding that $\mathrm{WO}_{4}{ }^{2-}$ adsorbs more strongly than $\mathrm{MoO}_{4}{ }^{2-}$. Both

11 models were able to simulate the effect at least in a qualitative sense, but for the DLM

12 there was a clear deviation at the two lowest $\mathrm{pH}$ values $(<\mathrm{pH} 4)$.

\section{Discussion}

This study suggests that the adsorption of $\mathrm{MoO}_{4}{ }^{2-}$ and $\mathrm{WO}_{4}{ }^{2-}$ to ferrihydrite can be described with two monodentate surface complexes in a surface complexation model. This does not rule out the existence of other surface complexes, such as the bidentate complex $\mathrm{Fe}_{2} \mathrm{O}_{2} \mathrm{XO}_{2}$, although they seem to be less important in affecting the shape of the adsorption envelope. In competitive systems with $\mathrm{PO}_{4}{ }^{3-}$, the model fits were not always satisfactory. It is possible that this is mainly related to the relatively large uncertainty of the values for the $\mathrm{PO}_{4}{ }^{3-}$ surface complexation constants. For example, slight changes in the $\mathrm{CD}$ values for the different $\mathrm{PO}_{4}{ }^{3-}$ surface complexes may produce equally good fits for $\mathrm{PO}_{4}{ }^{3-}$ in FITEQL, and substantially different fits for 
$1 \mathrm{MoO}_{4}{ }^{2-}$ and $\mathrm{WO}_{4}{ }^{2-}$ in competitive systems, compared to those presented here (data not

2 shown). This shows that a more extensive data set is needed for anion binding to

3 ferrihydrite, to constrain the surface complexation constants and to correctly predict

4 anion competition.

5

6 In general, the DLM complexes suggested here are consistent with the CCM complexes for goethite that were proposed by Goldberg and colleagues (Goldberg et al., 1996; Manning and Goldberg, 1996), although they used a combination of the D1 and D2 complexes. However, the DLM constants that were predicted by Dzombak and Morel (1990) using LFER proved to underestimate adsorption, particularly for $\mathrm{WO}_{4}{ }^{2-}$. Because Dzombak and Morel (1990) used only the first $\mathrm{p} K_{\mathrm{a}}$ value as a basis in their LFER, part of the explanation may be the small difference between the two $\mathrm{p} K_{\mathrm{a}}$ values for $\mathrm{MoO}_{4}{ }^{2-}$ and $\mathrm{WO}_{4}{ }^{2-}$. This enables the fully protonated D1 and D4 complexes to be of importance, in conflict with the LFER results. Still, this does not explain the observation that $\mathrm{WO}_{4}{ }^{2-}$ adsorbs much stronger than $\mathrm{MoO}_{4}{ }^{2-}$, as the two ions have similar $\mathrm{p} K_{\mathrm{a}}$ values. This shows that other factors may influence the relative affinity of various surface complexes. The issue why $\mathrm{WO}_{4}{ }^{2-}$ adsorbs so much more strongly than $\mathrm{MoO}_{4}{ }^{2-}$ is, however, unresolved and open to speculation.

It is probable that the model approach can be extended to other Fe oxides. Manning and Goldberg (1996) presented results on the $\mathrm{MoO}_{4}{ }^{2-}$ adsorption to goethite in singlesorbate systems and in competitive systems with $\mathrm{AsO}_{4}{ }^{3-}$ (Fig. 7). Hiemstra and Van Riemsdijk (1999) derived surface parameters and $\mathrm{AsO}_{4}{ }^{3-}$ constants for the application of CDM to this system. I found that $\mathrm{MoO}_{4}{ }^{2-}$ adsorption could be described rather well if the $\log K$ :s of the $\mathrm{C} 1$ and $\mathrm{C} 2$ complexes were slightly modified (to 17 and 12 , 
1 respectively, see Fig. 7). Despite the smaller value of $\log K_{\mathrm{C} 1}$, the $\mathrm{C} 1$ complex had to

2 be included to simulate the $\mathrm{AsO}_{4}{ }^{3-}$ competition in Fig. 7 correctly. Its replacement

3 with the bidentate complex $\mathrm{Fe}_{2} \mathrm{O}_{2} \mathrm{MoO}_{2}$ led to very poor fits at low $\mathrm{pH}$ (data not

4 shown).

5

6 Despite the apparent success with the CDM model proposed, it should be noted that

7 Rietra et al.'s results on the proton coadsorption stoichiometry for the $\mathrm{MoO}_{4}{ }^{2-}$ and

$8 \mathrm{WO}_{4}{ }^{2-}$ adsorption to goethite could not be accurately reproduced at $\mathrm{pH} 4.2$, although it

9 was closer to the observations at $\mathrm{pH}$ 6.1. Whereas the measured proton stoichiometry

10 was $\sim 1.24$ at $\mathrm{pH} 4.2$ after the addition of $0.8 \mathrm{mM} \mathrm{Na}_{2} \mathrm{MoO}_{4}$, the simulated

11 stoichiometry with my model was 1.08 . For $\mathrm{pH}$ 6.1, the figures were 1.42 and 1.33 ,

12 respectively. Possibly, the discrepancy may, after all, be explained if the $\mathrm{Fe}_{2} \mathrm{O}_{2} \mathrm{MoO}_{2}$

13 complex is present as an additional complex that is of some importance at low $\mathrm{pH}$. of a fully protonated complex, equivalent to molybdic or tungstic acid adsorbed onto

24 the oxide surface. The same observation was made for a system with goethite. These

\section{Conclusions}

This study demonstrates that the adsorption of $\mathrm{WO}_{4}{ }^{2-}$ to ferrihydrite is stronger than that of $\mathrm{MoO}_{4}{ }^{2-}$. The adsorption of these anions can be described by two monodentate surface complexes in both the DLM and the CDM. Molybdate and tungstate were adsorbed very strongly at low $\mathrm{pH}$, where the ions were able to displace $\mathrm{PO}_{4}{ }^{3-}$ from the ferrihydrite surface. This could be explained only if the model considers the presence results are of importance for assessments of Mo and W mobility in the environment. 


\section{Acknowledgements}

The Geological Survey of Sweden (SGU) and the Swedish Research Council (VR)

provided financial support to this study. Björn Evertsson is acknowledged for assistance with Mo and $\mathrm{W}$ analyses.

\section{References}

11 Balistrieri, L.S., Chao, T.T. 1990. Adsorption of selenium by amorphous iron oxyhydroxide and manganese dioxide. Geochim. Cosmochim Acta 54, 739-751.

Bibak, A., Borggaard, O.K. 1994. Molybdenum adsorption by aluminium and iron oxides and humic acid. Soil Sci. 158, 323-327.

Bourikas, K., Hiemstra, T., Van Riemsdijk, W.H. 2001. Adsorption of molybdate monomers and polymers on titania with a multisite approach. J. Phys. Chem. B 105, 2393-2403. $227,7-15$.

19 Cruywagen, J.J. 2000. Protonation, oligomerization, and condensation reactions of vanadate(V), molybdate(VI), and tungstate(VI). Adv. Inorg. Chem. 49, 127-182. Equilibria and thermodynamic quantities for the reactions with citrate. Polyhedron 14, 3481-3493.

Dzombak, D.A. and Morel, F.M.M. 1990. Surface Complexation Modeling - Hydrous Ferric Oxide. John Wiley \& Sons, New York. Sci. $163,109-114$. soils. Soil Sci. Soc. Am. J. 60, 425-432. 
1 Gustafsson, J.P. 2001. Modelling competitive anion adsorption on oxide minerals and an allophanecontaining soil. Eur. J. Soil Sci. 52, 639-653.

Herbelin, A.L., Westall, J.C. 1999. FITEQL 4.0: a Computer Program for Determination of Chemical Equilibrium Constants from Experimental Data; Report 99-01. Department of Chemistry, Oregon State University, Corvallis.

Hiemstra, T., Van Riemsdijk, W.H. 1996. A surface structural approach to ion adsorption: the charge distribution (CD) model. J. Colloid Interface Sci. 179, 448-508.

Hiemstra, T., Van Riemsdijk, W.H. 1999. Surface structural ion adsorption modeling of competitive binding of oxyanions by metal (hydr)oxides. J. Colloid Interface Sci. 210, 182-193.

Jacks, G. 1983. Undersökning av askprofiler från Nottingham, England. KHM Teknisk Rapport 104 (In 11 Swedish). Vattenfall, Stockholm, Sweden.

Manning, B.A., Goldberg, S. 1996. Modelling competitive adsorption of arsenate with phosphate and molybdate on oxide minerals. Soil Sci. Soc. Am. J. 60, 121-131.

Meima, J.A., van der Weijden, R.D., Eighmy, T.T, Comans, R.N.J. 2002. Carbonation processes in municipal solid waste incinerator bottom ash and their effect on the leaching of copper and molybdenum. Appl. Geochem. 17, 1503-1513.

Mikkonen, A., Tummavuori, J. 1993. Retention of tungsten(VI) by three Finnish mineral soils. Acta Agric. Scand., Sect. B, Soil Plant Sci. 43, 213-217.

Mikkonen, A., Tummavuori, J. 1994. Desorption of phosphate from three Finnish mineral soil samples

21 Rietra, R.P.J.J., Hiemstra, T., Van Riemsdijk, W.H. 1999. The relationship between molecular structure and ion adsorption on variable charge minerals. Geochim. Cosmochim. Acta 63, 3009-3015.

Schwertmann, U., Cornell, R.M. 2000. Iron Oxides in the Laboratory. Preparation and Characterization. John Wiley \& Sons, Weinheim.

Smith, R.M., Martell, A.E., Motekaitis, R.J. 2001. NIST Critically Selected Stability Constants of Metal Complexes Database. Version 6.0. NIST Standard Reference Database 46. US Department of Commerce, National Institute of Standards and Technology, Gaithersburg. its effect on arsenic adsorption. Wat. Res. 33, 3413-3422. 
1 Vunkova-Radeva, R., Schiemann, J., Mendel, R.R., Salcheva, G., Georgieva, D. 1988. Stress and

2 activity of molybdenum-containing complex in winter wheat seeds. Plant Physiol. 87, 533-535.

3 Wesolowski, D., Drummond, S.E., Mesmer, R.E., Ohmoto, H. 1984. Hydrolysis equilibria of

4 tungsten(VI) in aqueous sodium chloride solutions to $300^{\circ} \mathrm{C}$. Inorg. Chem. $23,1120-1132$.

5 Wood, S.A. \& Samson, I.M. 2000. The hydrothermal geochemistry of tungsten in granitoid

6 environments: I. Relative solubilities of ferberite and scheelite as a function of T, P, pH and $m_{\mathrm{NaCl}}$.

7 Econ. Geol. 95, 143-182. 
Table 1

Table of species for adsorption reactions in the DLM, and values of $\log K_{\mathrm{int}}{ }^{\mathrm{a}}$

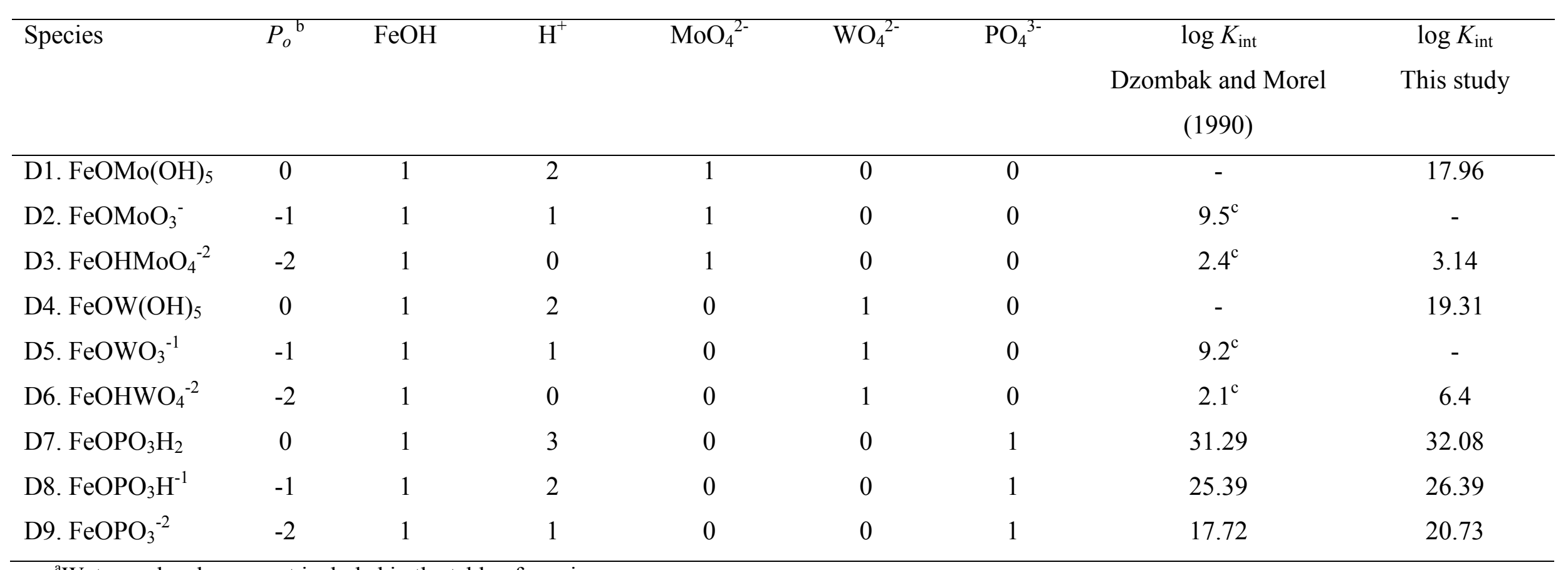

${ }^{a}$ Water molecules are not included in the table of species

${ }^{\mathrm{b}} P_{o}=\exp \left(-F \Psi_{o} / R T\right)$, where $F$ is the Faraday constant, $\Psi_{o}$ is the electrostatic potential in the $o$-plane, $R$ is the gas constant and $T$ is the absolute temperature

${ }^{\mathrm{c}}$ These values were estimated from linear free-energy relationships only 
Table 2

Table of species for adsorption reactions in the CDM, and values of $\log K_{\text {int }}{ }^{\mathrm{a}}$.

\begin{tabular}{|c|c|c|c|c|c|c|c|c|c|}
\hline Species & $P_{o}^{b}$ & $P_{b}^{b}$ & $\mathrm{FeOH}$ & $\mathrm{H}^{+}$ & $\mathrm{MoO}_{4}^{2-}$ & $\mathrm{WO}_{4}{ }^{2-}$ & $\mathrm{PO}_{4}{ }^{3-}$ & $\begin{array}{c}\log K_{\text {int }} \\
\text { (Gustafsson, 2001) }\end{array}$ & $\begin{array}{c}\log K_{\text {int }} \\
\text { This study }\end{array}$ \\
\hline $\mathrm{C} 1 . \mathrm{FeOMo}(\mathrm{OH})_{5}^{-0.5}$ & 0.5 & -0.5 & 1 & 2 & 1 & 0 & 0 & - & 18.28 \\
\hline $\mathrm{C} 3 . \mathrm{FeOW}(\mathrm{OH})_{5}^{-0.5}$ & 0.5 & -0.5 & 1 & 2 & 0 & 1 & 0 & - & 19.35 \\
\hline $\mathrm{C} 4 . \mathrm{FeOWO}_{3}{ }^{-1.5}$ & 0.5 & -1.5 & 1 & 1 & 0 & 1 & 0 & - & 14.07 \\
\hline C6. $\mathrm{Fe}_{2} \mathrm{O}_{2} \mathrm{POOH}^{-1}$ & 1 & -1 & 2 & 3 & 0 & 0 & 1 & 35.6 & 34.13 \\
\hline C7. $\mathrm{Fe}_{2} \mathrm{O}_{2} \mathrm{PO}_{2}^{-2}$ & 0.5 & -1.5 & 2 & 2 & 0 & 0 & 1 & 29.0 & 26.64 \\
\hline
\end{tabular}

${ }^{a}$ Water molecules are not included in the table of species

${ }^{\mathrm{b}} P_{o}=\exp \left(-F \Psi_{o} / R T\right)$ and $P_{b}=\exp \left(-F \Psi_{b} / R T\right)$, where $F$ is the Faraday constant, $\Psi_{o}$ and $\Psi_{b}$ are electrostatic potentials in the $o$ - and $b$-planes, $R$ is the gas constant and $T$ is the absolute temperature

${ }^{\mathrm{c}}$ The $P_{o}$ and $P_{b}$ values of this complex were previously set to 0.8 and -0.8 (Gustafsson, 2001), but were revised in this study. 
Table 3

Measured $\mathrm{pH}$ and dissolved concentrations of $\mathrm{MoO}_{4}, \mathrm{WO}_{4}$ and $\mathrm{PO}_{4}$ in the batch experiments

\begin{tabular}{|c|c|c|c|c|c|}
\hline \multicolumn{3}{|c|}{$\mathrm{MoO}_{4}$ added } & \multicolumn{3}{|l|}{$\mathrm{WO}_{4}$ added } \\
\hline Total Fe (M) & $\mathrm{pH}$ & $\mathrm{MoO}_{4}{ }^{2-}(\mu \mathrm{M})$ & Total Fe (M) & $\mathrm{pH}$ & $\mathrm{WO}_{4}{ }^{2-}(\mu \mathrm{M})$ \\
\hline \multirow[t]{16}{*}{$3 \times 10^{-3}$} & 3.13 & $<0.1$ & $3 \times 10^{-3}$ & 3.14 & $<0.1$ \\
\hline & 3.64 & & & 3.65 & \\
\hline & 5.20 & & & 5.23 & \\
\hline & 5.94 & & & 5.94 & \\
\hline & 6.30 & 0.15 & & 6.42 & \\
\hline & 6.59 & 0.63 & & 6.66 & \\
\hline & 6.87 & 3.15 & & 6.94 & \\
\hline & 7.07 & 7.7 & & 7.34 & 0.3 \\
\hline & 7.20 & 13.4 & & 7.73 & 1.1 \\
\hline & 7.21 & 19.5 & & 8.46 & 2.8 \\
\hline & 7.71 & 26.2 & & 8.75 & 5.8 \\
\hline & 7.85 & 31.6 & & 8.86 & 7.7 \\
\hline & 8.30 & 36.0 & & 9.06 & 11.4 \\
\hline & 8.46 & 38.8 & & 9.24 & 14 \\
\hline & 8.81 & 42.5 & & 9.37 & 17 \\
\hline & 9.76 & 47.5 & & 9.83 & 27 \\
\hline \multirow[t]{11}{*}{$1 \times 10^{-3}$} & 3.11 & $<0.1$ & $1 \times 10^{-3}$ & 3.11 & \\
\hline & 3.64 & & & 3.65 & $<0.1$ \\
\hline & 6.39 & 1.45 & & 6.43 & \\
\hline & 6.91 & 9.26 & & 7.29 & 1.7 \\
\hline & 7.09 & 15.4 & & 7.55 & 5.8 \\
\hline & 7.23 & 20.4 & & 7.81 & 10.1 \\
\hline & 7.29 & 25.7 & & 8.24 & 16.2 \\
\hline & 7.44 & 32.0 & & 8.38 & 19.6 \\
\hline & 7.71 & 38.2 & & 8.74 & 24.2 \\
\hline & 7.89 & 40.3 & & 8.94 & 27.8 \\
\hline & 8.39 & 44.4 & & 9.09 & 31.1 \\
\hline \multirow[t]{12}{*}{$3 \times 10^{-4}$} & 3.09 & 1.05 & $3 \times 10^{-4}$ & 3.10 & $<0.1$ \\
\hline & 3.65 & 0.72 & & 3.65 & \\
\hline & 6.06 & 19.5 & & 6.54 & 12.6 \\
\hline & 6.66 & 27.5 & & 7.02 & 21.9 \\
\hline & 6.83 & 33.2 & & 7.30 & 26.6 \\
\hline & 7.01 & 35.2 & & 7.41 & 29.1 \\
\hline & 7.13 & 39.4 & & 7.66 & 34.0 \\
\hline & 7.20 & 40.4 & & 7.90 & 36.7 \\
\hline & 7.28 & 44.6 & & 8.15 & 36.4 \\
\hline & 7.55 & 45.6 & & 8.31 & 38.7 \\
\hline & 8.53 & 48.9 & & 8.97 & 41.0 \\
\hline & 9.08 & 48.1 & & 9.12 & 43.4 \\
\hline \multicolumn{3}{|l|}{$\mathrm{PO}_{4}$ added } & \multicolumn{3}{|l|}{$\mathrm{PO}_{4}$ added } \\
\hline Tot-Fe (M) & $\mathrm{pH}$ & $\mathrm{PO}_{4}^{2-}(\mu \mathrm{M})$ & Tot-Fe (M) & $\mathrm{pH}$ & $\mathrm{PO}_{4}^{2-}(\mu \mathrm{M})$ \\
\hline \multirow[t]{12}{*}{$3 \times 10^{-3}$} & 3.10 & $<1$ & $1 \times 10^{-3}$ & 3.10 & 2 \\
\hline & 3.60 & & & 3.68 & 6 \\
\hline & 4.12 & & & 4.68 & 24 \\
\hline & 4.26 & & & 5.23 & 39 \\
\hline & 4.44 & & & 5.85 & 56 \\
\hline & 4.70 & & & 6.26 & 69 \\
\hline & 5.07 & & & 6.45 & 71 \\
\hline & 5.70 & & & 6.62 & 82 \\
\hline & 6.39 & & & 6.94 & 92 \\
\hline & 6.82 & 1 & & 7.18 & 98 \\
\hline & 7.49 & 11 & & 7.48 & 108 \\
\hline & 8.06 & 28 & & 7.73 & 120 \\
\hline
\end{tabular}




\begin{tabular}{|c|c|c|c|c|c|}
\hline \multicolumn{3}{|c|}{$\mathrm{PO}_{4}+\mathrm{MoO}_{4}$ added, $1 \times 10^{-3} \mathrm{M}$ total $\mathrm{Fe}$} & \multicolumn{3}{|c|}{$\mathrm{PO}_{4}+\mathrm{WO}_{4}$ added, $1 \times 10^{-3} \mathrm{M}$ total $\mathrm{Fe}$} \\
\hline $\mathrm{pH}$ & $\mathrm{PO}_{4}{ }^{2-}(\mu \mathrm{M})$ & $\mathrm{MoO}_{4}{ }^{2-}(\mu \mathrm{M})$ & $\mathrm{pH}$ & $\mathrm{PO}_{4}{ }^{2-}(\mu \mathrm{M})$ & $\mathrm{WO}_{4}{ }^{2-}(\mu \mathrm{M})$ \\
\hline 3.13 & 14 & 1.28 & 3.14 & 11 & $<0.1$ \\
\hline 3.83 & 35 & 1.92 & 3.84 & 31 & \\
\hline 4.63 & 56 & 4.6 & 4.68 & 54 & \\
\hline 4.97 & 58 & 8.84 & 5.16 & 69 & 0.8 \\
\hline 5.36 & 63 & 17.5 & 5.67 & 81 & 2.9 \\
\hline 5.74 & 71 & 26.6 & 6.10 & 93 & 5.9 \\
\hline 6.08 & 77 & 34.6 & 6.42 & 99 & 10.9 \\
\hline 6.40 & 79 & 41.4 & 6.66 & 104 & 16.6 \\
\hline 6.69 & 80 & 41.9 & 6.89 & 100 & 19.3 \\
\hline 6.94 & 86 & 46.3 & 7.11 & 102 & 22.5 \\
\hline 7.2 & 89 & 46.7 & 7.32 & 111 & 29.0 \\
\hline 7.45 & 104 & 49.3 & 7.55 & 116 & 33.1 \\
\hline
\end{tabular}


Table 4

Intrinsic DLM adsorption constants (standard deviations in paranthesis) from experimental data for molybdate and tungstate adsorption to ferrihydrite ${ }^{a}$

Molybdate

\begin{tabular}{lccc}
\hline Total Fe $(\mathrm{M})$ & $\log K_{\mathrm{D} 1}^{\mathrm{INT}}$ & $\log K_{\mathrm{D} 3}^{\mathrm{INT}}$ & WSOS/DF \\
\hline $3 \times 10^{-3}$ & $17.96^{\mathrm{b}}$ & $3.05(0.039)$ & 23 \\
$1 \times 10^{-3}$ & $18.28(0.087)$ & $3.19(0.092)$ & 3.4 \\
$3 \times 10^{-4}$ & $17.73(0.063)$ & $3.37(0.13)$ & 3.7 \\
Weighted average & 17.96 & 3.14 &
\end{tabular}

Tungstate

\begin{tabular}{lccc}
\hline Total Fe $(\mathrm{M})$ & $\log K_{\mathrm{D} 4}{ }^{\mathrm{INT}}$ & $\log K_{\mathrm{D} 6}{ }^{\mathrm{INT}}$ & WSOS/DF \\
\hline $3 \times 10^{-3}$ & $19.31^{\mathrm{b}}$ & $6.60(0.037)$ & 4.9 \\
$1 \times 10^{-3}$ & $19.31^{\mathrm{b}}$ & $6.21(0.046)$ & 2.5 \\
$3 \times 10^{-4}$ & $19.31(0.064)$ & $6.24(0.13)$ & 1.7 \\
Weighted average & 19.31 & 6.40 &
\end{tabular}

Phosphate

\begin{tabular}{lcccc}
\hline Total Fe $(\mathrm{M})$ & $\log K_{\mathrm{D} 7}{ }^{\mathrm{INT}}$ & $\log K_{\mathrm{D} 8}{ }^{\mathrm{INT}}$ & $\log K_{\mathrm{D} 9}{ }^{\mathrm{INT}}$ & WSOS/DF \\
\hline $1 \times 10^{-3}$ & $32.08(0.18)$ & $26.39(0.29)$ & $20.73(0.60)$ & 2.7
\end{tabular}

${ }^{\mathrm{a}}$ The method of Dzombak and Morel (1990) was used to obtain error estimates and weighted averages.

${ }^{\mathrm{b}}$ Fixed at this value to achieve convergence. 
Table 5

Intrinsic CDM adsorption constants (standard deviations in paranthesis) from experimental data for molybdate and tungstate adsorption to ferrihydrite ${ }^{a}$

Molybdate

\begin{tabular}{lccc}
\hline Total Fe $(\mathrm{M})$ & $\log K_{\mathrm{C} 1}^{\mathrm{INT}}$ & $\log K_{\mathrm{C} 2}^{\mathrm{INT}}$ & WSOS/DF \\
\hline $3 \times 10^{-3}$ & $18.28^{\mathrm{b}}$ & $11.07(0.043)$ & 20 \\
$1 \times 10^{-3}$ & $18.57(0.066)$ & $11.13(0.12)$ & 3.3 \\
$3 \times 10^{-4}$ & $18.02(0.17)$ & $11.5(0.12)$ & 4.2 \\
Weighted average & 18.28 & 11.17 &
\end{tabular}

Tungstate

\begin{tabular}{lccc}
\hline Total Fe $(\mathrm{M})$ & $\log K_{\mathrm{C} 3}{ }^{\mathrm{INT}}$ & $\log K_{\mathrm{C} 4}{ }^{\mathrm{INT}}$ & WSOS/DF \\
\hline $3 \times 10^{-3}$ & $19.35^{\mathrm{b}}$ & $14.23(0.034)$ & 1.7 \\
$1 \times 10^{-3}$ & $19.35^{\mathrm{b}}$ & $13.97(0.040)$ & 1.4 \\
$3 \times 10^{-4}$ & $19.35(0.13)$ & $13.88(0.080)$ & 2.0 \\
Weighted average & 19.35 & 14.07 &
\end{tabular}

Phosphate

\begin{tabular}{lcccc}
\hline Total Fe $(\mathrm{M})$ & $\log K_{\mathrm{C} 5}{ }^{\mathrm{INT}}$ & $\log K_{\mathrm{C} 6}{ }^{\mathrm{INT}}$ & $\log K_{\mathrm{C} 7}{ }^{\mathrm{INT}}$ & WSOS/DF \\
\hline $1 \times 10^{-3}$ & $31.53(0.15)$ & $34.13(1.46)$ & $26.64(0.30)$ & 0.6
\end{tabular}

${ }^{\mathrm{a}}$ The method of Dzombak and Morel (1990) was used to obtain error estimates and weighted averages.

${ }^{\mathrm{b}}$ Fixed at this value to achieve convergence. 


\section{Figure captions}

Fig. 1. Adsorption of molybdate ( $50 \mu \mathrm{M}$ added) to ferrihydrite in single-sorbate systems. Points are observations, and lines are fits with the DLM (upper panel) or CDM (lower panel). The dotted line is the model fit obtained with the non-optimised constants in Table 1, whereas the solid line represents the fit obtained with the weighted average constants in Tables 4 and 5.

Fig. 2. Adsorption of tungstate ( $50 \mu \mathrm{M}$ added) to ferrihydrite in single-sorbate systems. Points are observations, and lines are fits with the DLM (upper panel) and the CDM (lower panel). The dotted line is the model fit obtained with the nonoptimized constants in Table 1, whereas the solid line represents the fit obtained with the weighted average constants in Tables 4 and 5.

Fig. 3. Adsorption of phosphate $(200 \mu \mathrm{M}$ added $)$ to ferrihydrite in single-sorbate systems. Points are observations, and lines are fits with the DLM (upper panel) and the CDM (lower panel). The dotted line is the model fit obtained with the nonoptimized constants in Tables 1 and 2, whereas the solid line represents the fit obtained with the weighted average constants in Tables 4 and 5.

Fig. 4. Adsorption of molybdate to ferrihydrite in the presence of phosphate, at a total Fe concentration of $1 \times 10^{-3} \mathrm{M}$. Points are observations, and lines are fits with the DLM (upper panel) and the CDM (lower panel), using the weighted average constants in Tables 4 and 5. 
Fig. 5. Adsorption of tungstate to ferrihydrite in the presence of phosphate, at a total Fe concentration of $1 \times 10^{-3} \mathrm{M}$. Points are observations, and lines are fits with the DLM (upper panel) and the CDM (lower panel), using the weighted average constants in Tables 4 and 5.

Fig. 6. Adsorption of phosphate to ferrihydrite, in the absence or presence of molybdate and tungstate), at a total Fe concentration of $1 \times 10^{-3} \mathrm{M}$. Points are observations, and lines are fits with the DLM (upper panel) or CDM (lower panel), using the weighted average constants in Tables 4 and 5.

Fig. 7. Adsorption of molybdate to goethite, in the absence or presence of arsenate. The data are from Manning and Goldberg (1996). The lines are CDM fits using log $K_{\mathrm{C} 1}=17$ and $\log K_{\mathrm{C} 2}=12$, see text. 

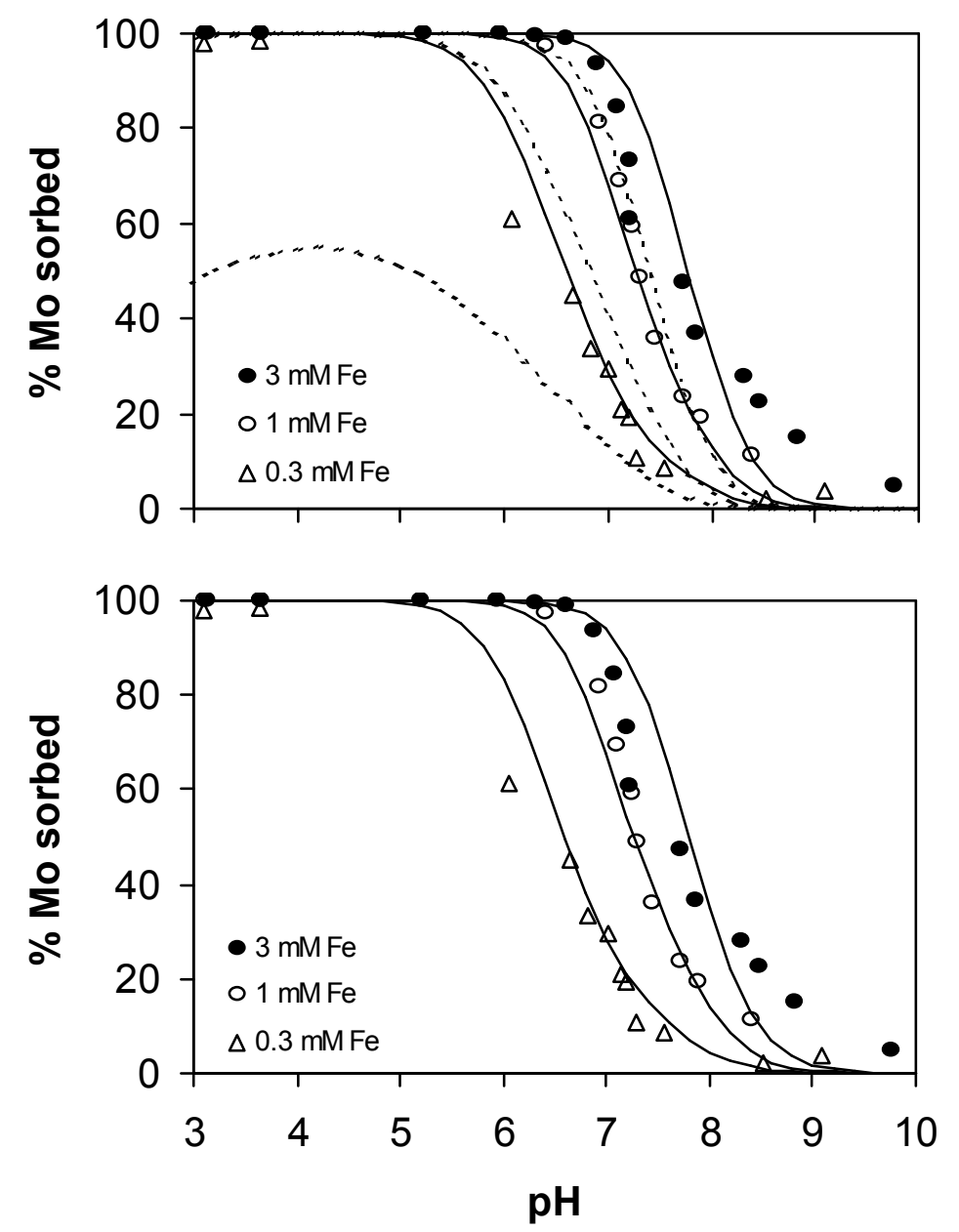

Fig. 1 

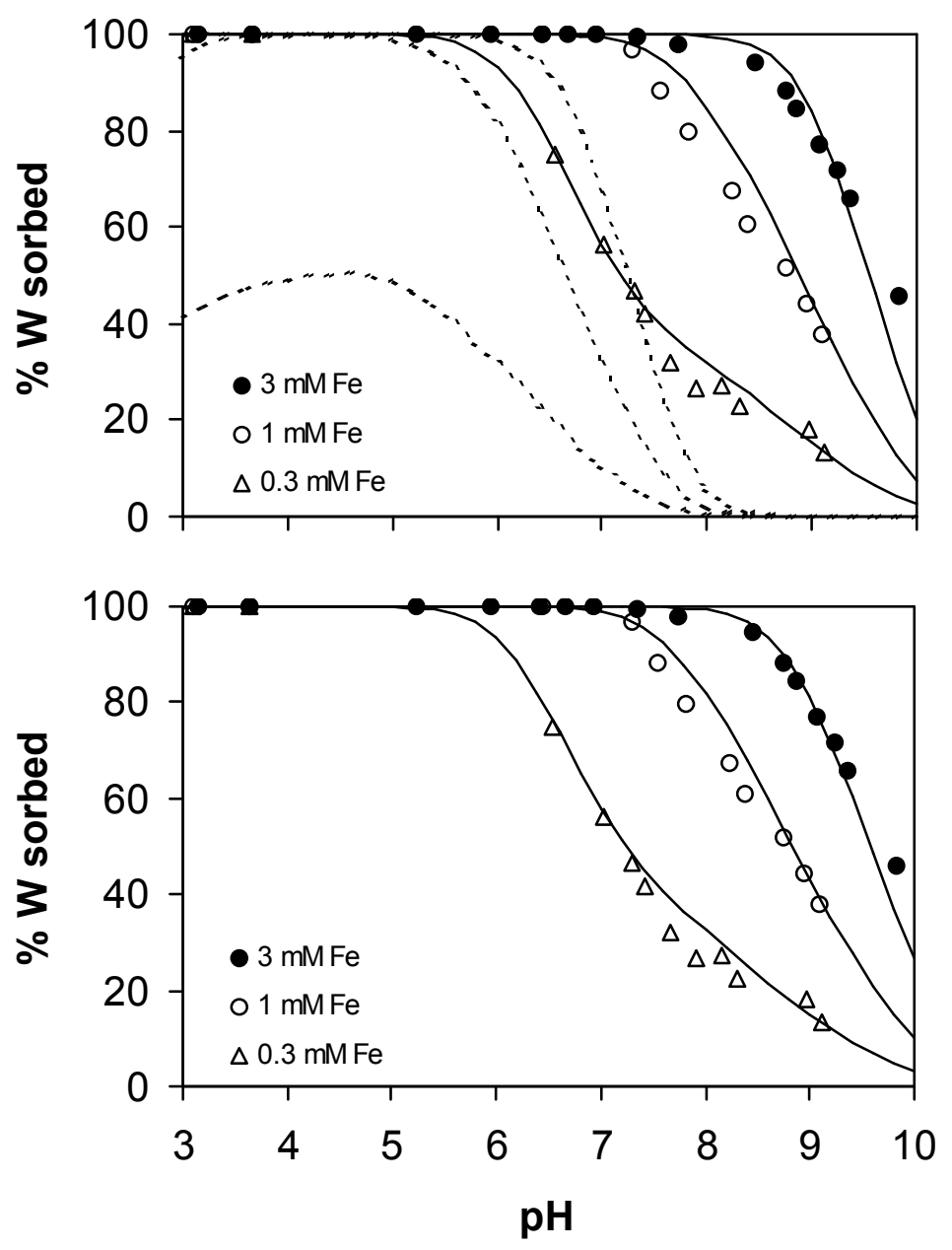

Fig. 2 